\title{
Southwestward extent of chlorophyll-enriched waters from the Peruvian and equatorial upwellings between Tahiti and Panama
}

\author{
Y. Dandonneau \& G. Eldin \\ Groupe SURTROPAC, Centre ORSTOM, BP A5, Nouméa, New-Caledonia
}

\begin{abstract}
The transition zone between waters deriving from the Peruvian and equatorial upwellings, and oligotrophic waters of the Central South Tropical Pacific, was examined by sea-surface chlorophyll sampling carried out by merchant ships on the Tahiti-Panama track. The results from 118 transects (December 1979 to September 1985) show that this transition is generally associated with convergences between the westward South Equatorial Current and eastward flows, as indicated by contemporaneous temperature sections obtained from expendable bathythermographs. The transition position varies between 5 and $17^{\circ} \mathrm{S}$ and variations occur mostly on time scales of a month or less. The Tuamotu atolls $\left(15\right.$ to $22^{\circ} \mathrm{S}, 135$ to $\left.150^{\circ} \mathrm{W}\right)$ were observed to be reached by waters deriving from the upwellings on $14 \%$ of the transects; this might help to explain the anomalous abundance of life on these atolls. The 1982-1983 El Niño resulted in a fall in chlorophyll concentrations in the Eastern Tropical Pacific, but did not cause a significant change of the position of the transition.
\end{abstract}

\section{INTRODUCTION}

The Peruvian and equatorial upwellings in the eastern Pacific are of particular interest to oceanographers for their contributions to marine life and to global airsea carbon dioxide exchange (Bacastow et al. 1980, Walsh 1981). Photosynthesis in this region is indeed very active due to intense upward motion of deep, nutrient-rich seawater. El Niño/Southern Oscillation (ENSO) episodes are known to lessen the intensity of the upwelling in most of the region, resulting in a drop in phytoplankton biomass and in carbon fixation rates (Barber \& Chavez 1983, Dandonneau 1986). On a smaller time scale, the size of the cool water tongue which marks the equatorial upwelling at the sea surface (Wyrtki 1981) varies seasonally, showing its maximum extension and lowest temperatures in August, and its minimum extension and highest temperatures in March and April (Robinson 1976). Seasonal variations of primary production would generally be expected to follow a similar pattern, but available information is too scarce to permit any definite conclusions. When information exists, it does not always show a primary productivity maximum during the austral winter associated with the maximum intensity of the equatorial upwelling (Owen \& Zeitzschel 1970).
Dessier \& Donguy (1985) describe a seasonal cycle at the equator in the eastern Pacific with a chlorophyll and zooplankton maximum in August, and a smaller chlorophyll maximum from March to May; these features agree with the seasonal variations in equatorial upwelling shown by Wyrtki (1981). One may thus expect that the size of the area influenced by the upwelling varies in relation to the size of the equatorial cool water tongue. This size would partly determine the total amount of carbon fixed by the equatorial upwelling ecosystem. Drastic variations in the size and position of the productive habitat in the area of the Galapagos Islands were documented by satellite sea color data (Feldman 1986). This oceanic region is also known for having low chlorophyll content in nutrientrich surface waters south of the equator (Thomas 1979), which can perturb the relation between the upwelling strength and the size of the enhanced productivity area.

South of the equatorial upwelling, the central South Pacific is in a quasi steady state with a 100 to $150 \mathrm{~m}$ deep mixed layer exhausted in nutrients, and a low biomass (Desrosieres \& Wauthy 1972). The zooplankton populations in the equatorial upwelling ecosystem and in the central South Pacific are strikingly different (McGowan 1974, Dessier 1983). The boundary be- 
tween the 2 ecosystems is examined here using about 4000 sea-surface chlorophyll concentrations (Fig. 1) measured in samples taken by merchant ships on 2 tracks between Tahiti and Panama (SURTROPAC programme, Centre ORSTOM de Noumea). These data represent 135 transects covering the period January 1980 to December 1985 . The transects generally show a relatively high sea-surface chlorophyll concentration (SSCC) in the equatorial area, and low SSCC in the Central South Pacific. The boundary between the 2 zones is marked by a more or less pronounced step-like SSCC variation, which we shall designate the upwelled waters / oligotrophic waters transition' (UW-OW transition). Vertical profiles of temperature from expendable bathythermographs (XBTs) launched from the same ships are analysed in order to provide a contemporaneous knowledge of the water masses' structure.

\section{MATERIAL AND METHODS}

Sea-surface chlorophyll concentrations (SSCC) were obtained according to the method described by Dandonneau (1982). Sampling and filtration (Millipore HA filters, $13 \mathrm{~mm}$ in diameter) were carried out by the crews of merchant ships. The filters were returned when the ships called at Nouméa (New Caledonia) and measurements were made in the laboratory. Pigment fluorescence was measured without solvent extraction: the membrane filters were placed in a specially adapted fluorometer door, and the fluorescence of the filter surface measured. Small filtered volumes $(20 \mathrm{ml})$, and chlorophyll concentrations rarely exceeding $1 \mathrm{mg}$ $\mathrm{m}^{-3}$, limited the density of cells on the filters, so that self-absorption of the fluoresced light was negligible. Fluorescence is then linearly related to the chlorophyll concentration. Long storage (weeks to months) at ambient temperature causes degradation of the chlorophyll; moreover the results represent the sum of chlorophyll and pheopigments, and must be considered as only an index of the phytoplankton abundance. The risk of bias between different transects cannot be neglected.

On the other hand, when the SSCC data from one transect are considered, the UW-OW transition generally appears as an abrupt step in SSCC values (Fig. 2) and its position can be known with reasonable precision. In order to preserve this information, the SSCC data were processed transect by transect. Each one of the 135 merchant ships' voyages between Tahiti and Panama thus corresponds to an observation of the UWOW transition at a given position and date. The position of the UW-OW transition was objectively fixed from the best fit of a hyperbolic tangent function with the SSCC observations at longitude $X$ :

$$
\mathrm{Y}=\mathrm{A}+0.5 \mathrm{~B}\left(1+\tanh \mathrm{C}\left[\mathrm{X}-\mathrm{X}_{0}\right]\right)
$$

where $A=$ the mean $\mathrm{SSCC}$ value in the oligotrophic waters of the Central South Pacific observed during the transect; $B=$ the SSCC increase from oligotrophic waters to upwelled waters; $\mathrm{X}_{0}=$ the position of the point of inflexion and will be assigned hereafter to the position of the UW-OW transition; and $\mathrm{C}=$ the slope of the curve at $\mathrm{X}_{0} . \mathrm{X}$ was assigned to the longitude of the observations rather than to the latitude, because, for a part of the track through the Southern Tuamotu Islands, one latitude would correspond to 2 positions

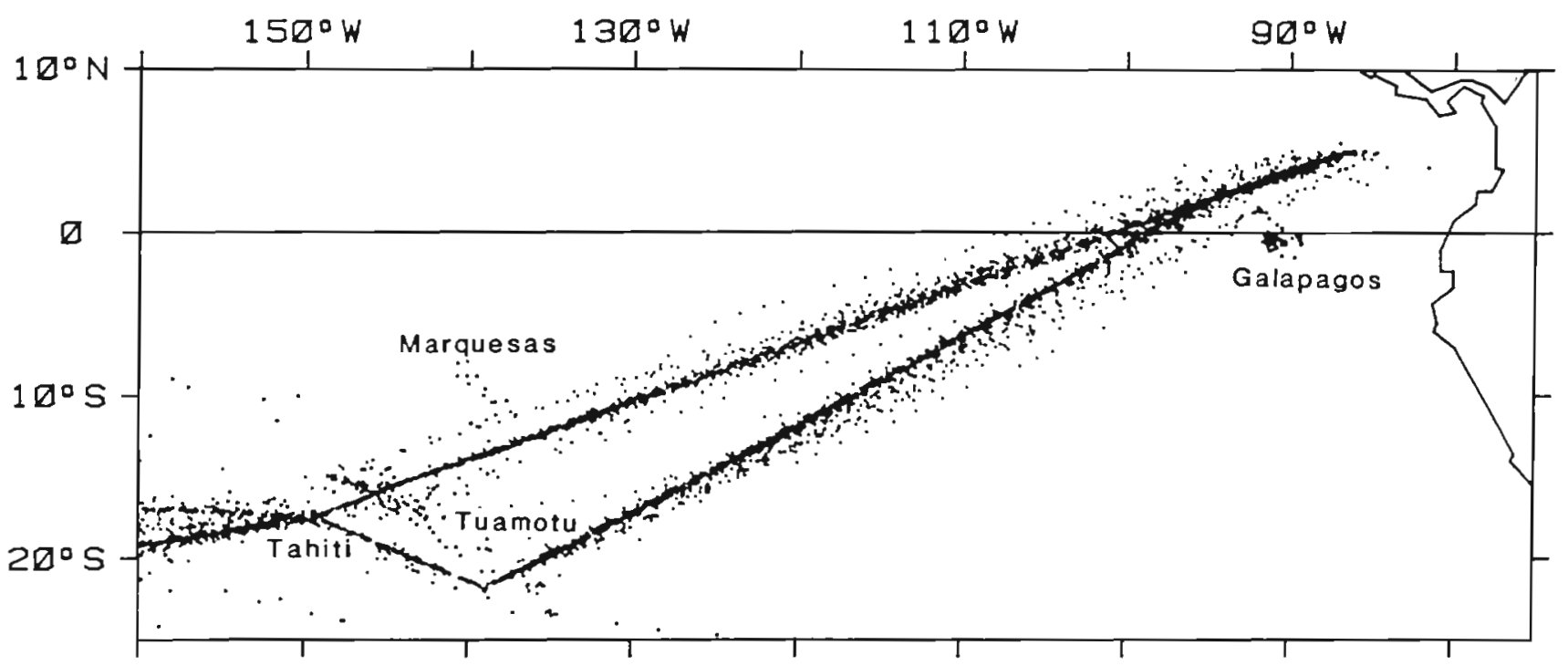

Fig. 1. Distribution of data on the northerly and southerly ship tracks from Tahiti to Panama (December 1979 to September 1985) 


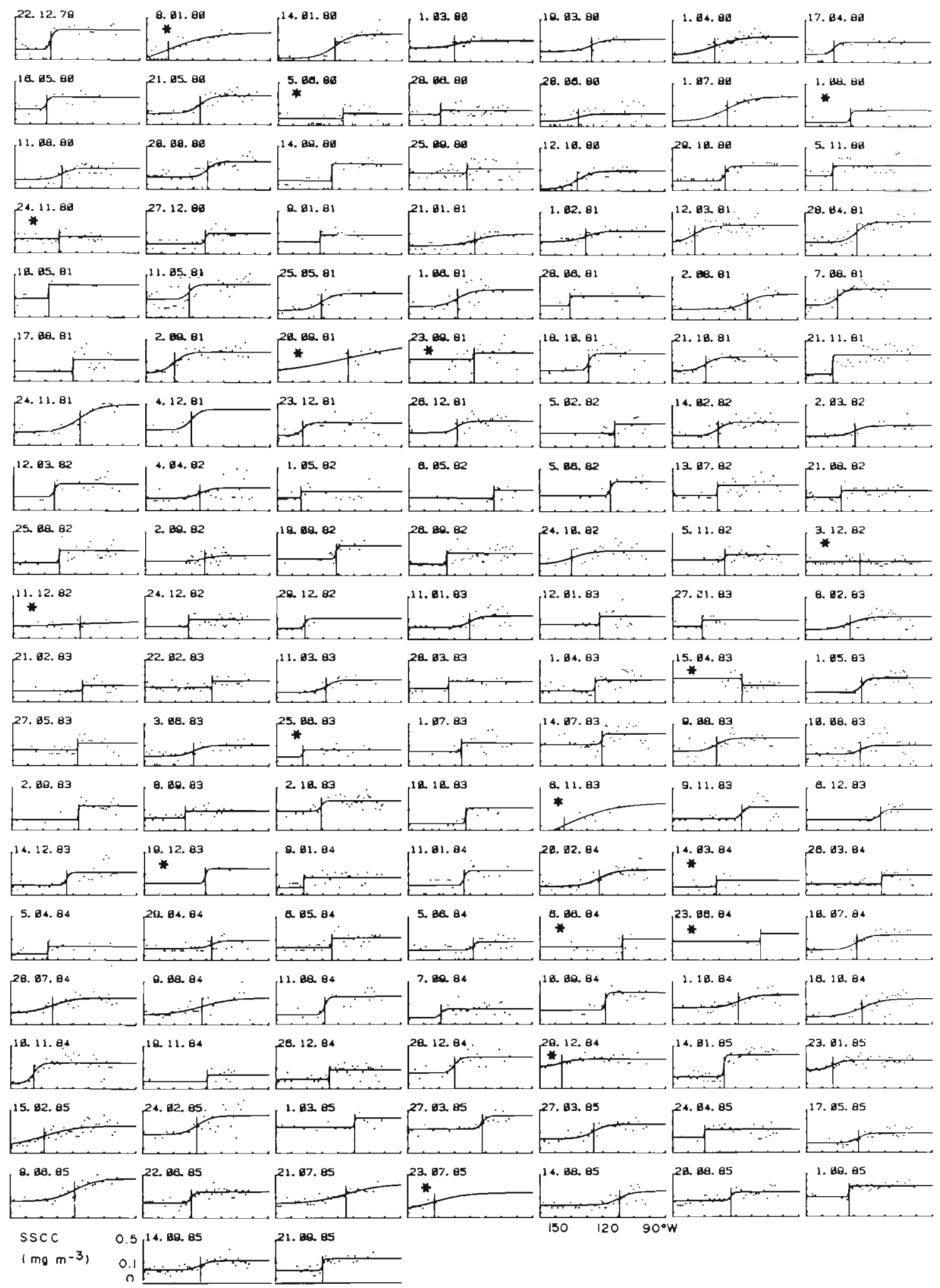

Fig. 2. SSCC versus longitude for the 135 Tahiti-Panama transects, and best fits of $\mathrm{Y}=\mathrm{A}+\mathrm{B}\left(1+\tanh \mathrm{C}\left[\mathrm{X}-\mathrm{X}_{0}\right]\right)$. Asterisks mark the 17 transects which were excluded from further analysis 

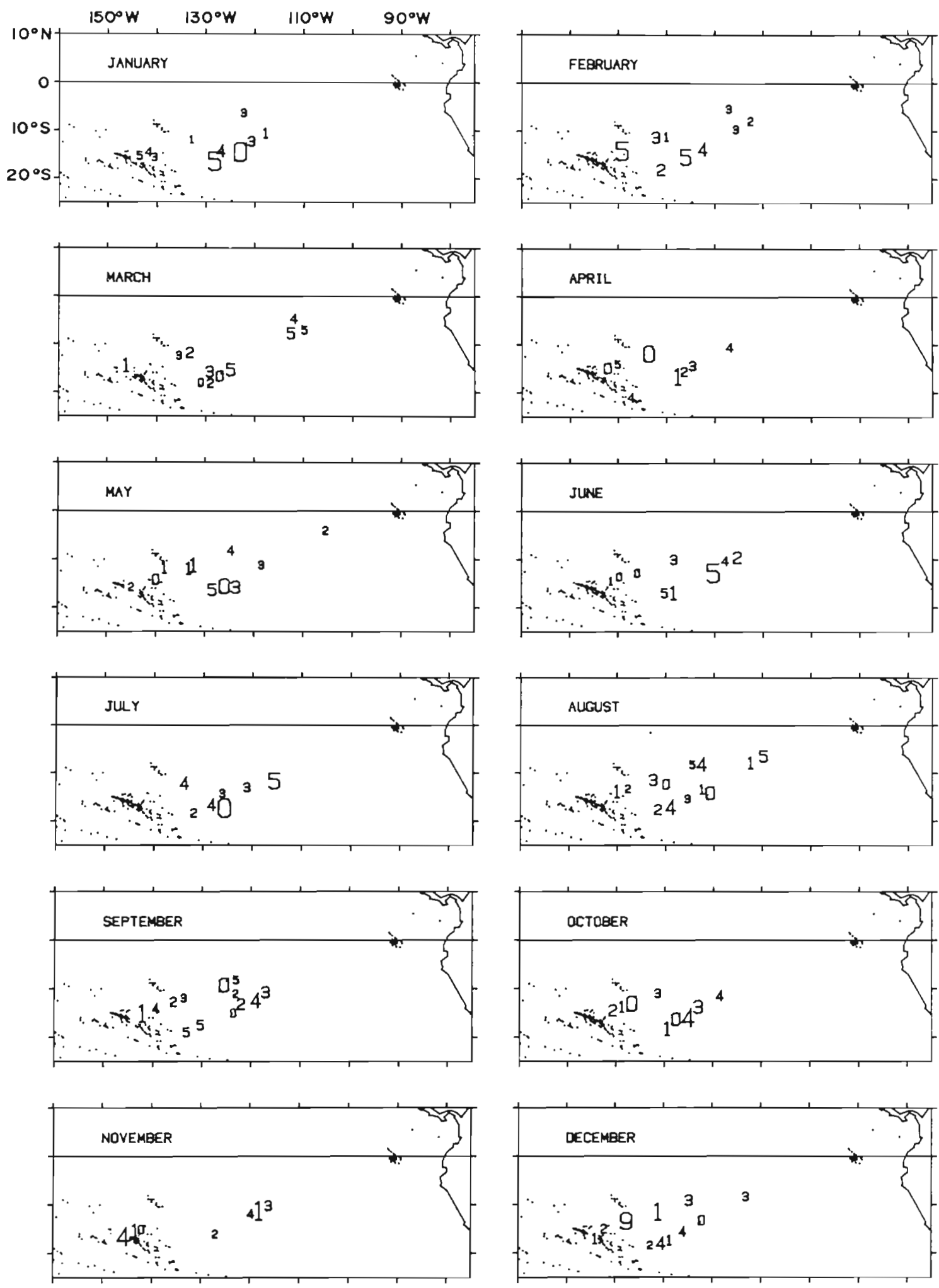

Fig. 3. Monthly positions of the UW-OW transition. Digits refer to the year (e.g. ' 3 ' corresponds to a transition observed in 1983). The size of the digit is related to the difference in SSCC between upwelled and oligotrophic waters. The many dots on the charts are islands or atolls 
(Fig. 1). The constants $A, B, C$ and $X_{0}$ were estimated using a continuous approach technique (adapted from the Newton-Raphson method) tending to minimize the sum of $(\text { SSCC-Y })^{2}$.

For a few transects, the solution obtained at the first attempt was unrelated to the UW-OW transition. Generally, the cause was the high and variable chlorophyll concentrations in the 'productive habitat' of the equatorial upwelling (Feldman 1986) which accounted for most of the variance and attracted the solution. A log-normal transform was applied to all the SSCC values to remedy this difficulty. Some aberrant solutions remained, resulting from a few high SSCC values on the oligotrophic side of the UW-OW transition which were either due to island mass effects (Dandonneau \& Charpy 1985) or to vertical mixing in winter south of $20^{\circ} \mathrm{S}$ (Dandonneau \& Gohin 1984). These values were also removed, after it was verified that they originated from within a few miles of an island, or from south of $20^{\circ} \mathrm{S}$ during the winter months.

Temperature data were obtained from expendable bathythermographs (XBTs). Routine corrections and elimination of errors were made in the laboratory. Temperature data are also presented transect by transect, in the form of vertical sections. Some of the XBT records do not reach $400 \mathrm{~m}$ depth. They were retained, however in order to preserve the spatial definition along these sections; thus only the surface isotherms (temperatures greater than $20^{\circ} \mathrm{C}$ ) were considered. Geostrophic currents could not be significantly computed in such conditions, and the discussion will be based on currents inferred from visual examination of the vertical sections and relative to the $20^{\circ} \mathrm{C}$ isotherm. According to geostrophic principles, a poleward (equatorward) increase of the isotherms' depth will be interpreted as a westward (eastward) flow, and a trough will be interpreted as a convergence. Conclusions thus are not derived from absolute flows, but only from relative surface currents, which seem however reliable for interpretation of surface phytoplankton features. In this way, 101 out of the 135 SSCC transects are documented by contemporaneous XBT sections. When XBT transects with large gaps and SSCC transects with gaps or imprecise UW-OW transition are excluded, 65 'good' SSCC transects paralleled by XBT data allow an attempt to associate the UW-OW transition to the distribution of water masses. Of these 65 transects, 54 will be considered as representative of normal conditions while the remaining 11 refer to the El Nin̄o conditions which prevailed in 1982-1983.

\section{RESULTS}

SSCC values generally greater than $0.1 \mathrm{mg} \mathrm{m}^{-3}$ in the eastern part of the ship's tracks and less than this around Tahiti allow in most cases a good agreement between the hyperbolic tangent model and the observations. The best fits of Eqn (1) are presented in Fig. 2. The position of the UW-OW transition, given by the inflexion point of the curve, is identified by a date. Results were inadequately based for 20 Sep 1981 , 6 Nov 1983, 23 Jun 1984 and 23 Jul 1985, due to sampling interruption during these transects. For some other transects, the position obtained for the UW-OW transition looks unreliable, due to gaps in sampling (1 Aug 1980, 25 Jun 1983 and 19 Dec 1983), uncertainty in the position of the boundary between the 2 distinct ecosystems (8 Jan 1980, 5 Jun 1980, 24 Nov 1980, 23 Sep 1981, 14 Mar 1984, 6 Jun 1984 and 29 Dec 1984) or

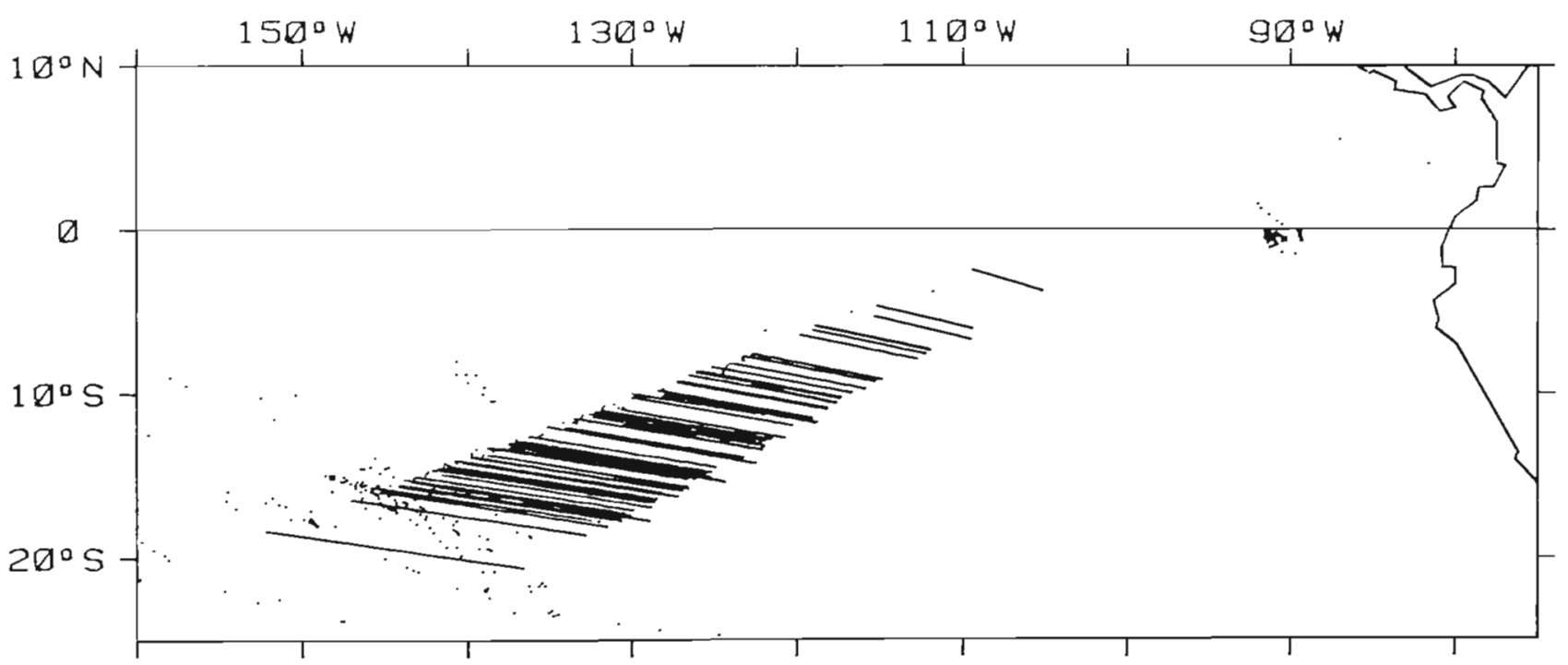

Fig. 4. Homogenization of the UW-OW transition positions on both tracks. Positions (latitude, longitude) on the southern track have been transformed in order to have the same mean and standard deviation as the positions on the northern track 
abnormal situations during the 1982-1983 ENSO (3 Dec 1982, 11 Dec 1982 and 15 Apr 1983). Results from these 17 transects are excluded for the rest of the analysis. The remaining transects provide estimates of the position of the UW-OW transition which are plotted on Fig. 3. For all months, this position appears to be highly variable, ranging between 127 and $158^{\circ} \mathrm{W}$ on the northern shipping track and between 110 and $132^{\circ} \mathrm{W}$ on the southern one. Differences between months are not striking; one may however note a slight tendency for the enriched waters to exert an influence farther southwestwards in November and December.

The northern and southern tracks are not far away from one another and we can assume that the UW-OW transition displacements on both tracks are related to the same causes. We can thus refer these causes to a single index. The results from the southern track were empirically made compatible with those from the northern track as follows: a linear transformation was applied to the latitudes of the southern track UW-OW transitions in such a way that the transformed latitudes had the same mean and standard deviation as the UWOW transition latitudes obtained on the northern track. A similar transformation was applied to the longitudes. The vectors corresponding to these transformations are shown in Fig. 4. They are approximately parallel to the surface isotherms which delineate the equatorial tongue of cool water, confirming the role of the equatorial upwelling for SSCC variations in this region. The latitude of the UW-OW transition (results from the northern track plus transformed results from the southern track) appears to be dominated by short-term variations (Fig. 5). A least squares Fourier series analysis indicates that the $1 \mathrm{yr}$ period has a small and uncertain amplitude $\left(0^{\circ} 29^{\prime}\right.$ in latitude) and accounts for only $1.13 \%$ of the total variance. The semi-annual period has a negligible amplitude. None of the Fourier components between 6 yr and 3 mo has an amplitude greater than $1^{\circ}$ in latitude. Periods less than 3 mo account for $60 \%$ of the total variance, indicating that short-term displacements of the UW-OW transition (the 'noise') are more important than a hypothetical large-scale signal. A more complete spectral analysis could not be performed because of the limited number of observations and their irregular spacing in time.

Temperature versus depth sections are presented in Fig. 6 to 9, together with the SSCC data obtained during the same ship's voyage. Sections made during the 1982-1983 ENSO are presented in Fig. 9 and are considered separately. When the slope of the isotherms reverses, forming a trough around $15^{\circ} \mathrm{S}$, the UW-OW transition is often found in this trough, which corresponds to the convergence between the South Equatorial Current and a pronounced eastward flow (Fig. 6). This is the most frequent situation, which was observed on 31 transects. On other transects, the convergence is indistinct; then, the entire South Equatorial Current has high SSCC and the UW-OW transition is found between the southern edge of this current and the northern edge of a pronounced eastward flow (Fig. 7); the results from 10 transects are relevant to this situation. On 13 transects, the UW-OW transition was found in the South Equatorial Current; the southern part of this current was then characterized by low SSCC (Fig. 8). The 1982-1983 ENSO episode includes 11 transects (the first on 26 Sep 1982, the last on 1 May 1983). The warming and deepening of the surface mixed layer at the equator can be seen on the temperature sections presented in Fig. 9. The southward slope of the isotherms between 5 and $15^{\circ} \mathrm{S}$ indicates however that the South Equatorial Current persisted through the period, and that, on most sections, it was characterized by waters with high SSCC. Exceptions are the observations of 3 and 11 Dec 1982, where SSCC between Tahiti and Panama showed no trend (Fig. 2), and the observation of 15 Apr 1983 (Fig. 9) where high SSCCs are in

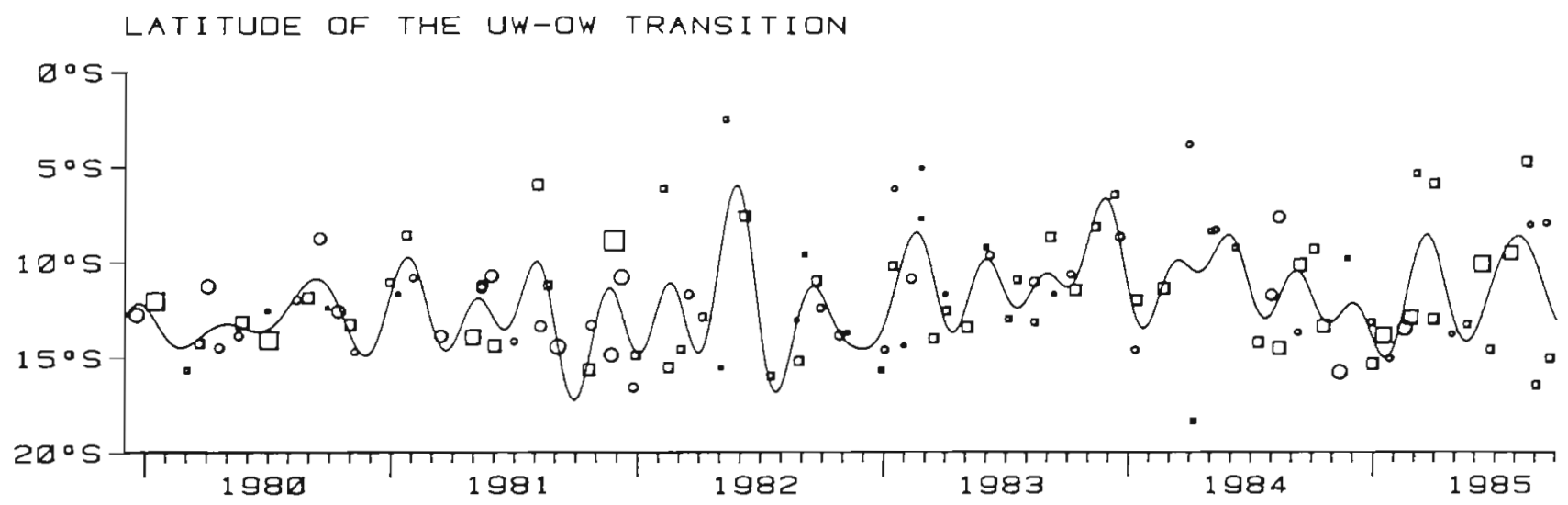

Fig. 5. Time evolution of the UW-OW transition latitude. Circles: results obtained on the northern track. Squares: homogenized results from the southern track. The size of the squares or circles is related to the difference in SSCC between upwelled and oligotrophic waters. The continuous line represents the results of a low pass Fourier filter (cutoff period: 3 mo) 
NORTHERN TRACK

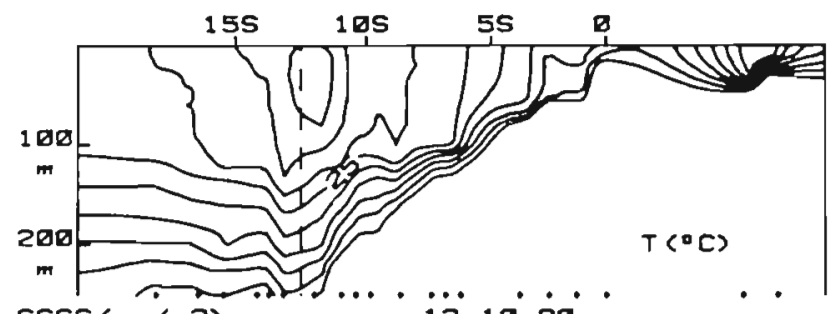

$\operatorname{sscc}(m g / m 3)$
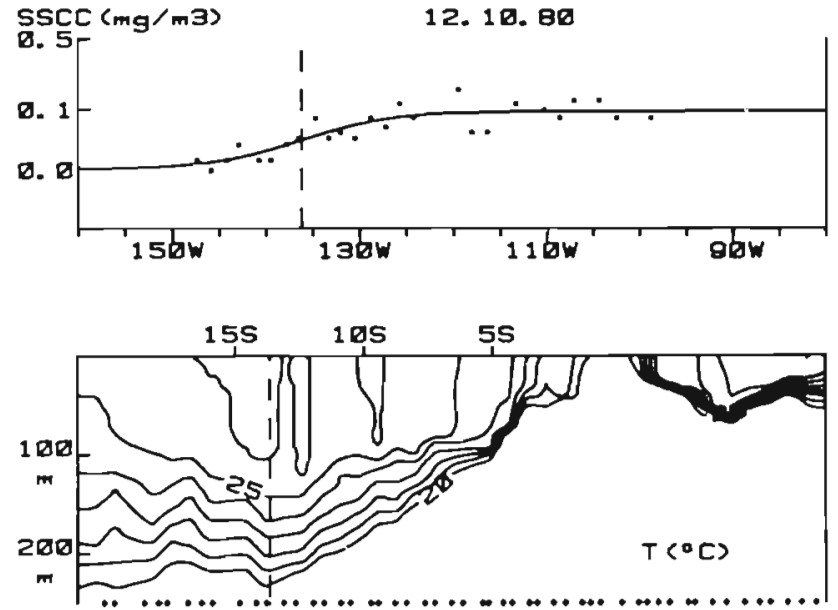

$\operatorname{sscc}(\mathrm{mg} / \mathrm{m} 3)$
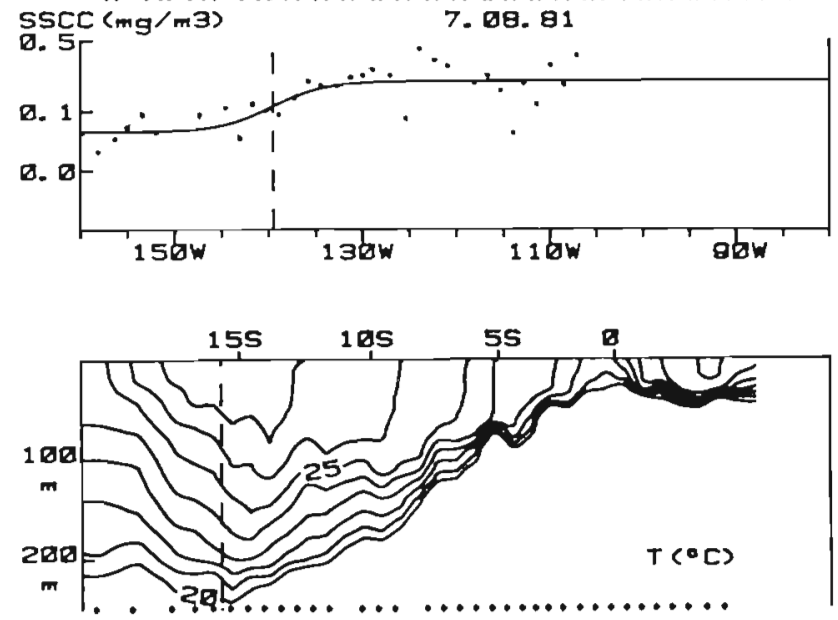

$\operatorname{sscc}(\dot{m} g ; \operatorname{mos}$

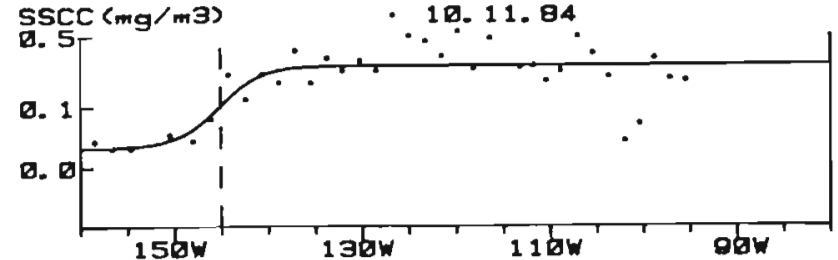

SOUTHERN TRACK

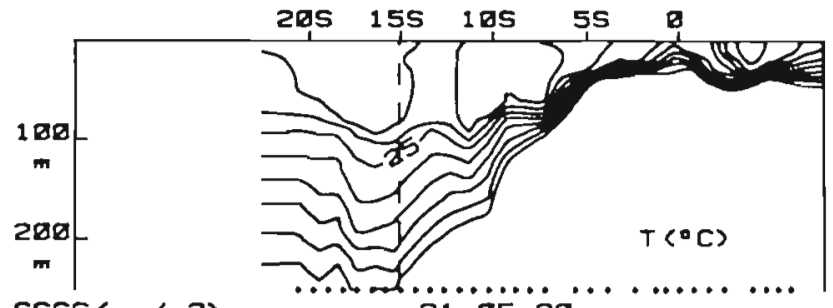

$\operatorname{sscc}(\mathrm{mg} / \mathrm{m} 3)$
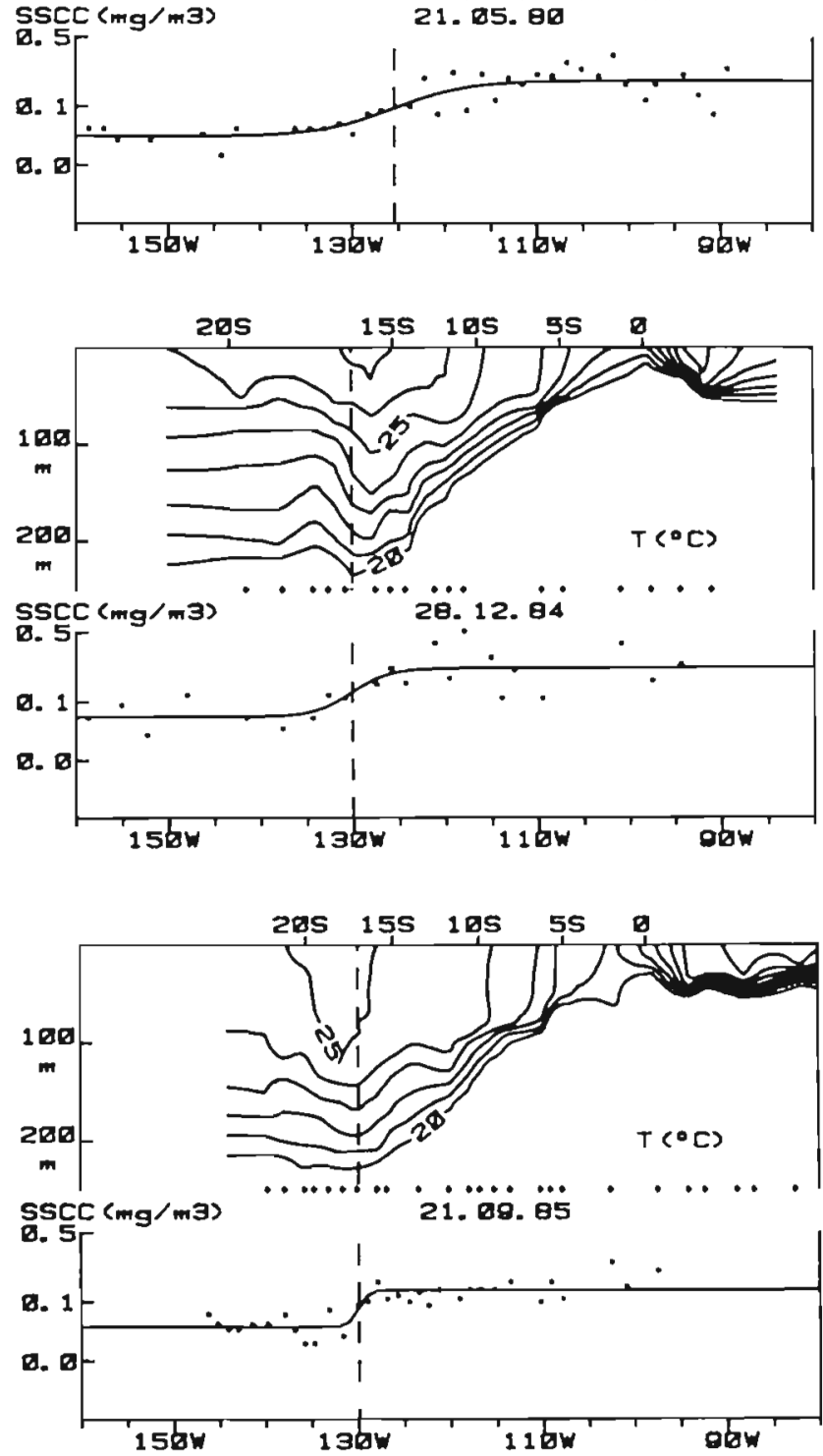

Fig. 6. Temperature and SSCC sections showing a UW-OW transition associated with a distinct trough in the isotherms. This trough corresponds to a convergence between the South Equatorial Current and an eastward flow

the southwest and low SSCCs are between $5^{\circ} \mathrm{S}$ and Panama.

\section{DISCUSSION}

The belt enriched by equatorial upwelling appears narrow on the chart drawn by Koblentz-Mishke et al.
(1970): the contour of daily carbon fixation equal to $100 \mathrm{mg} \mathrm{m}^{-2}$ cuts the Tahiti-Panama ship's track at about $7^{\circ} \mathrm{S}$. Our results indicate that the upwelling influence on SSCC is felt as far as $13^{\circ} 30^{\prime} \mathrm{S}$ (the mean latitude of the UW-OW transition on the northern track; Fig. 5), with peaks at $15^{\circ} \mathrm{S}$ on the northern track and $18^{\circ} \mathrm{S}$ on the southern track (Fig. 3). It also appears in 
NORTHERN TRACK
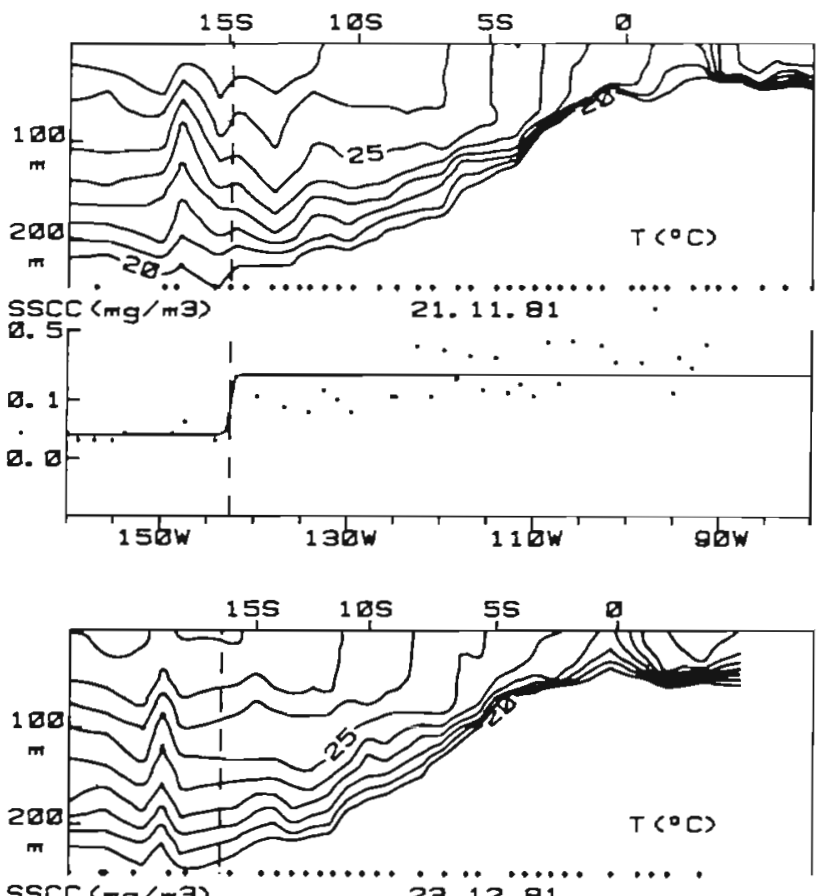

$\operatorname{sscc}(\pi m g / m 3)$

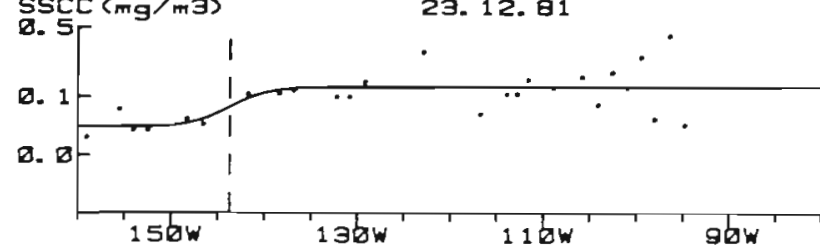

SOUTHERN TRACK
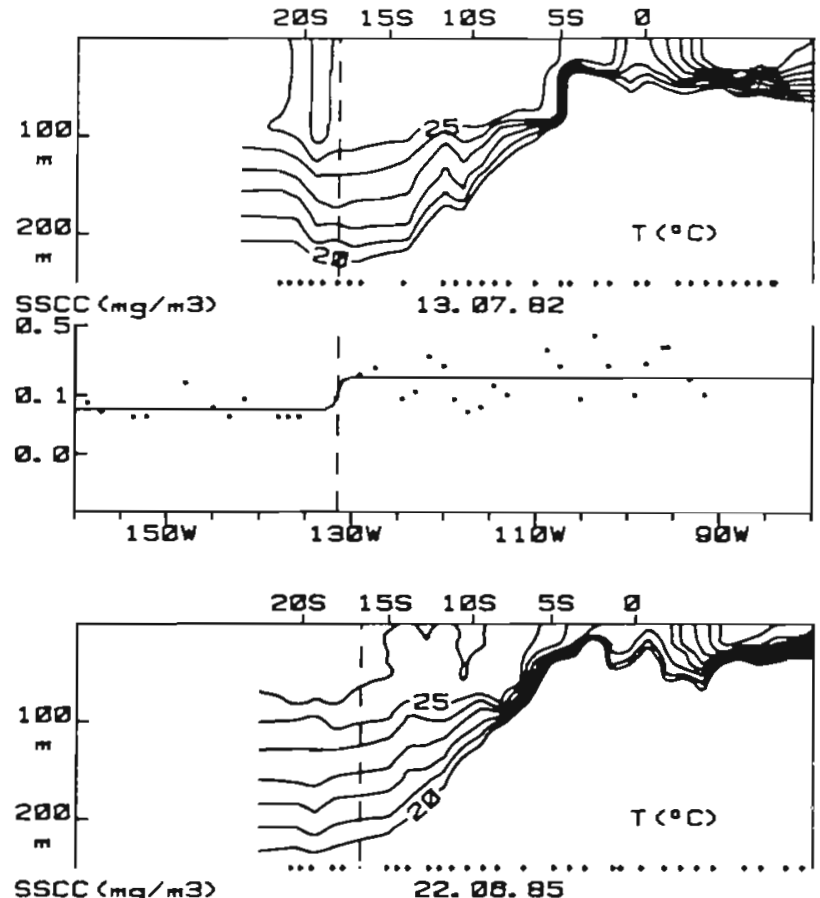

$\operatorname{sscc}(m g / m 3)$

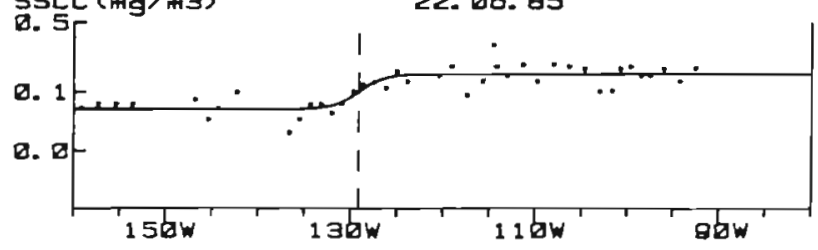

Fig. 7. Temperature and SSCC sections showing a UW-OW transition associated with an imprecise convergence zone south of the South Equatorial Current

the present work that the relatively high SSCC values on the equator side of the UW-OW transition are found in most cases in the entire South Equatorial Current and are limited to the south by the South Equatorial Countercurrent or related eastward flows (Fig. 6 \& 7). This not well-established current has been described between $130^{\circ} \mathrm{W}$ and America by Tsuchiya (1974) and between 160 and $150^{\circ} \mathrm{W}$ over shorter time intervals by Eldin (1983). It can be split into several small branches which transport eastwards water with higher temperature and slightly lower salinity than the surrounding South Equatorial Current. According to Eldin (1983), transport by this current is weak and irregular, and the positions of its branches are unstable. Furthermore, an explanation by zonal currents is distorted by the tracks' direction which makes a small angle with the parallels (Fig. 1). Nevertheless, the South Equatorial Current was entirely occupied by high SSCC at $41(31+10)$ transects for which the transition was found at the convergence between the 2 currents (Fig. 6 \& 7). Surface water coming from the west, as indicated by an equatorward slope of the isotherms, has a low chlorophyll content. The 13 transects for which the
UW-OW transition was found in the South Equatorial Current represent a different situation: then, an important part of this current was characterized by low SSCC (Fig. 8). It can be noted however that a small local inversion of the isotherms slope often coincided with the UW-OW transition (Fig. 8: observations of $14 \mathrm{Dec}$ 1983, 6 May 1984 and 9 Nov 1983); 8 out of the 13 transects present such an inversion of the isotherms at the UW-OW transition, and 11 present a salinity minimum (according to salinity data contemporaneous with the SSCC observations, not presented here) which also marks eastwards flows (Eldin 1983). Such slope inversions are common in all the transects, and coincidences with the UW-OW transition are coarse; it might thus be countered that the coincidences result simply from chance. The present results however demonstrate that relatively high SSCCs related to the upwelling ecosystem occupy a large part of the South Equatorial Current and are generally limited to the south by eastward currents. These currents indeed transport oligotrophic, nutrient-exhausted water from the west.

The time variations of the position of the UW-OW 
NORTHERN TRACK

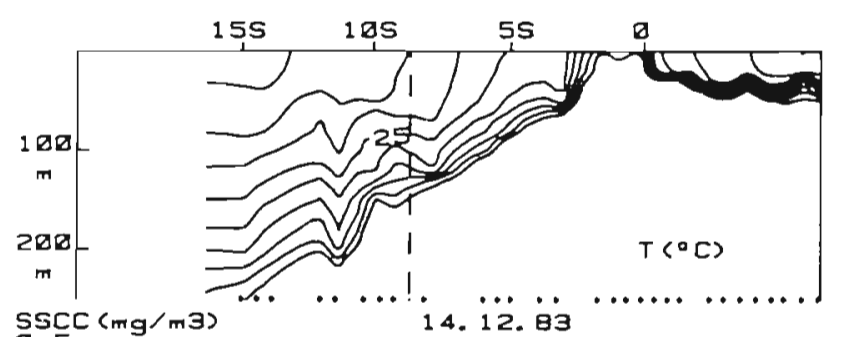

$\operatorname{sscc}(m g / m)$
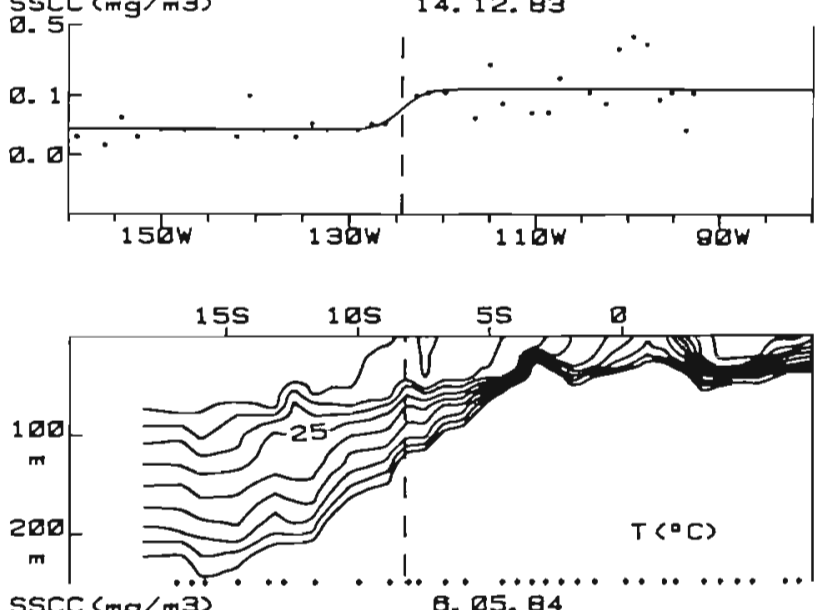

$\operatorname{sscc(~}(\mathrm{mg} / \mathrm{m} 3)$

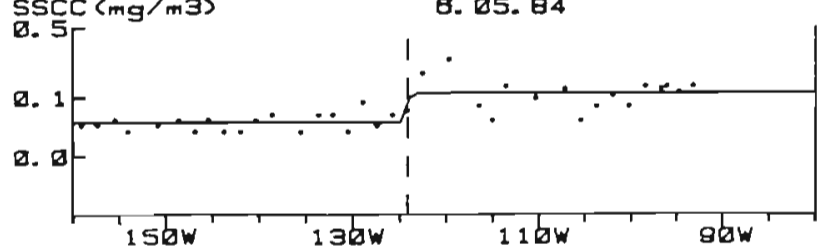

SOUTHERN TRACK

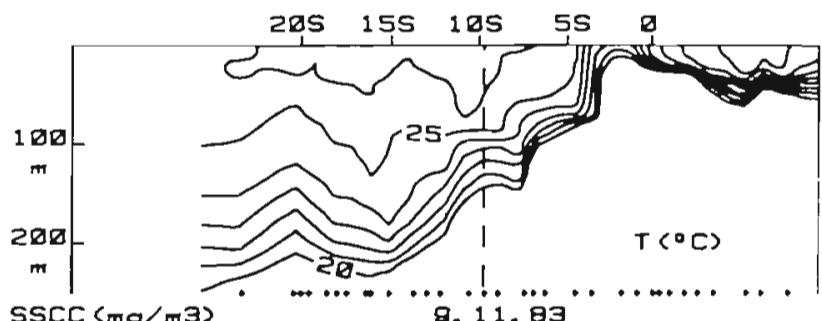

$\operatorname{sscc}(m g / m)$
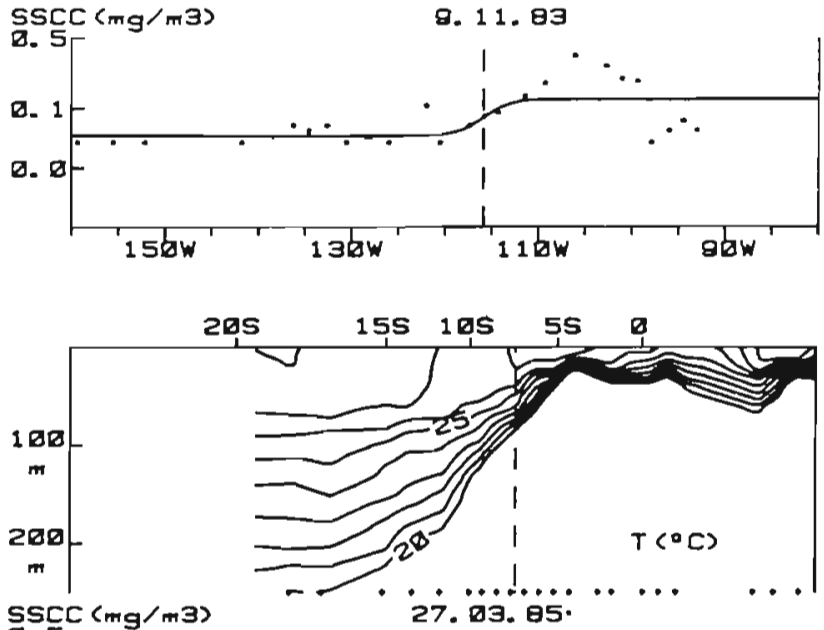

$\operatorname{ssccc}(m g / m 3)$ 27.033.

ฮ.

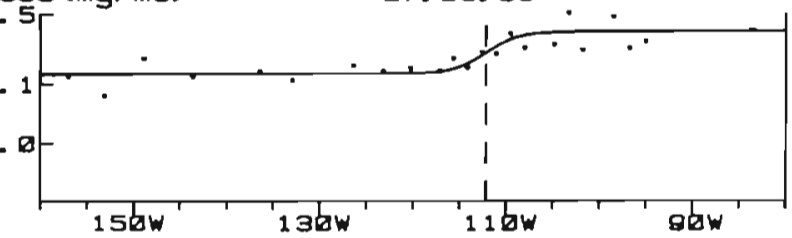

Fig. 8. Temperature and SSCC sections showing a UW-OW transition in the South Equatorial Current. During such sections, the southern part of this current was characterized by low SSCC

transition shown in Fig. 5 appear to be dominated by short-term variations. These may result from several factors. The positions found for the UW-OW transition are subject to error: the SSCC gradient at the UW-OW transition is sometimes weak (Fig. 2) and the noise in SSCC cannot be resolved when sampling $90 \mathrm{~km}$ apart. This error however is probably not more than $1^{\circ}$ in latitude. The eastward flows, which bound the upwelled waters ecosystem, are unstable and their latitudes vary between 7 and $14{ }^{\circ} \mathrm{S}$ (Eldin 1983), covering most of the zone where the transition moves to and fro. The Peruvian and equatorial upwellings, which are the sources of the chlorophyll-enriched waters, are located far from our area of interest. Assimilation of nutrients while these waters are drifting at the surface is slowed by intense grazing (Walsh 1976) which is considered to be the cause of abnormally low chlorophyll concentrations in nutrient-rich waters in this region. Small variations of the speed of nutrient assimilation can drastically affect the time and place where oligotrophy takes over from mesotrophy. A rapid assimilation of nutrients would thus explain the easternmost UW-OW transitions located in the South Equatorial Current (Fig. 8). Equatorial upwelling at $150^{\circ} \mathrm{W}$ has been shown to have a pulsatory regime, in relation with trade wind bursts (Showers 1982, Wyrtki \& Eldin 1982), also representing a source of variability. Thus, the Peruvian and equatorial upwelling strength can undergo seasonal variations (Wyrtki 1981), but the size of the area where SSCC is influenced by upwelling is dominated by short-term variations which mask the effects of these seasonal variations.

The period of observations covers the 1982-1983 El Niño episode. Except a few transects for which no transition was observed (Fig. 2: 3 and 11 Dec 1982, 15 Apr 1983), it does not seem that El Niño caused an equatorward retreat of the UW-OW transition (Fig. 5). A decrease in SSCC in the eastern tropical Pacific during the El Niño has been reported (Barber \& Chavez 1983, Dandonneau 1986) but the winds favourable to upwelling off Peru did not weaken and upwelling persisted through the event; nevertheless, the upwelled water was lower in nutrients than during non El Niño conditions (Barber \& Chavez 1983). The poleward 
NORTHERN TRACK

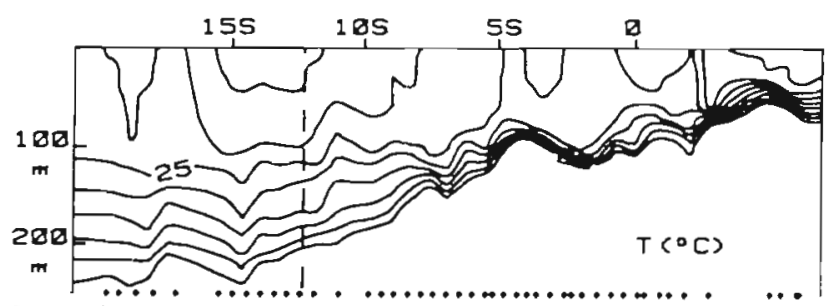

$\operatorname{sscc}(m g / m)$

घ. 5

๑. 1

D.

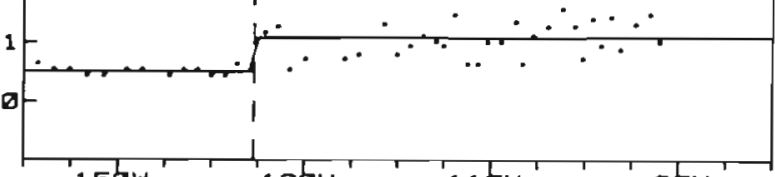

28. 89.82

abw 11 bw
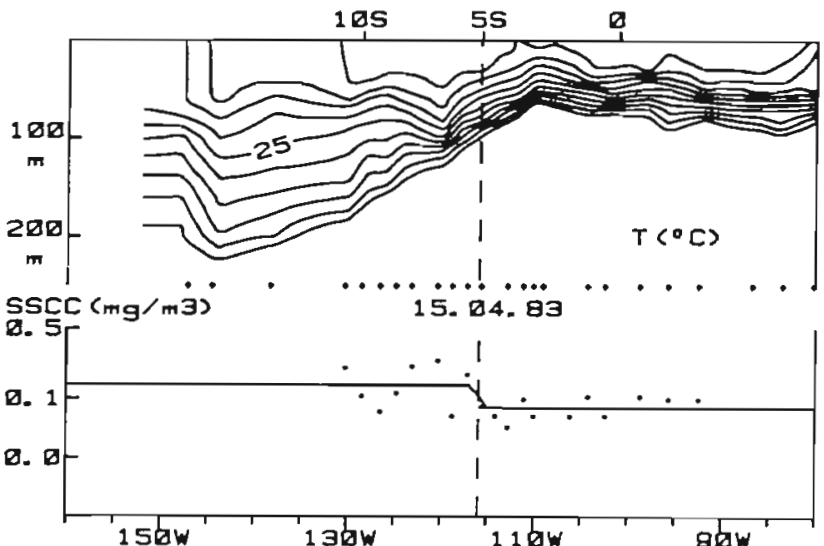

SOUTHERN TRACK

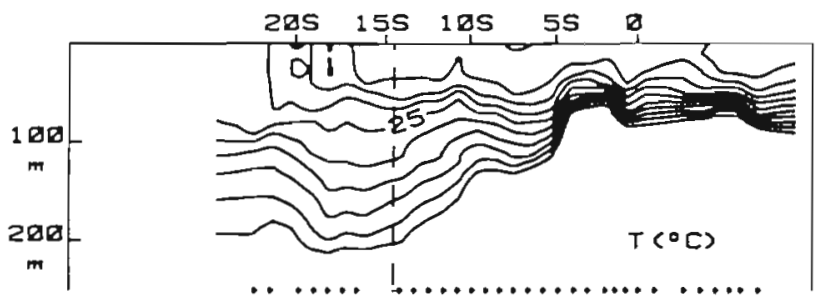

$\operatorname{sscc}(m g / m 3)$
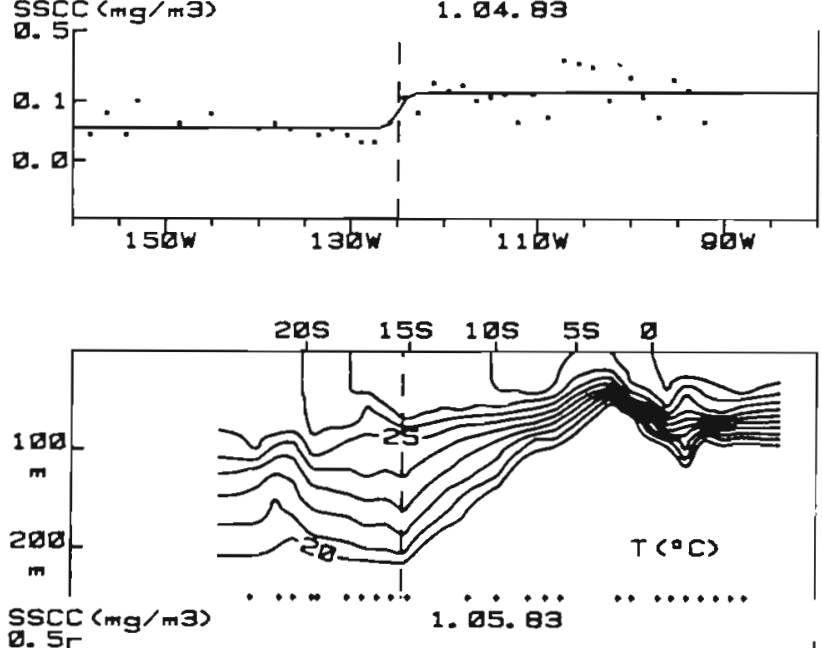

อsc

ฮ. 1

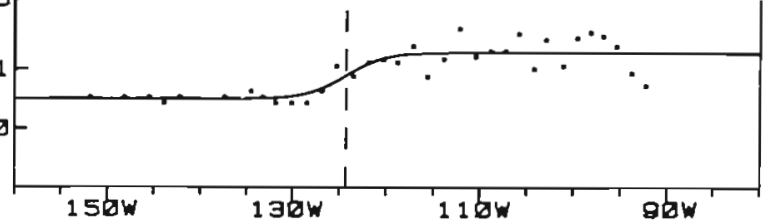

Fig. 9. Temperature and SSCC sections during the 1982-1983 El Niño. The South Equatorial Current was still characterized by higher SSCC

slope of the isotherms between 5 and $15^{\circ} \mathrm{S}$ associated with the South Equatorial Current continued to be related to relatively high SSCC (Fig. 9). The surprising inversion of the UW-OW transition on $15 \mathrm{Apr} 1983$ might perhaps be due to vertical mixing after a typhoon (Iverson 1977): austral summer typhoons had abnormally easterly trajectories in 1983 and typhoon Veena passed Tahiti on 12 April. Vertical mixing and phytoplankton growth could follow westward to $115^{\circ} \mathrm{W}$ (Fig. 9). This hypothesis must be considered with caution because SSCC sampling was interrupted west of $130^{\circ} \mathrm{W}$, and a trough in the isotherms can be seen at about $143^{\circ} \mathrm{W}$ which could indicate a normal, nondetected, UW-OW transition. Setting apart this transect, the UW-OW transition during the El Nino episode was found on 8 occasions at the convergence between the South Equatorial Current and the South Equatorial Countercurrent or water masses with uncertain geostrophic motions; on 2 occasions, it was found in the South Equatorial Current. Conditions during the EI Niño thus were greatly modified in coastal areas (Feld- man 1986), but did not differ qualitatively from normal conditions in offshore areas.

The Tuamotu archipelago in the southwest of the studied area has been described as an oligotrophic area (Desrosieres \& Wauthy 1972). It is indeed situated on the oligotrophic side of the UW-OW transition. However, the transition sometimes reaches these atolls (Fig. 3). These intrusions of relatively rich waters represent an alternate regime for the Northern Tumotu atolls which in their anomolous abundance of life have been compared to oases in a desert (Rougerie \& Wauthy 1986). Of the 118 UW-OW transition latitudes plotted in Fig. 5, 16 (i.e. $14 \%$ ) reach $15^{\circ} \mathrm{S}$ and correspond to high SSCCs surrounding these atolls. The ocean can thus episodically contribute to the food of atoll communities as considered by Dandonneau \& Charpy (1985) who observed chlorophyll depletion around the Tuamotu atolls.

The transition from an ecosystem connected with the upwellings of the Eastern Pacific to the oligotrophic ecosystem of the Central South Pacific is seen here 
using chlorophyll concentrations at the ocean surface. Surface chlorophyll has been shown to be a good index of chlorophyll content and primary productivity (Lorenzen 1970, Platt \& Herman 1983). A risk of error exists however, expecially in oligotrophic areas where inverse relations between SSCC and water-column productivity have sometimes been found (Hayward \& Venrick 1982). We are here partly dealing with oligotrophic waters and prudence is necessary. The complexity of the region which sometimes presents nutrient inversions (Thomas 1972) also calls for prudence. The SSCC increase from which we have inferred the position of the UW-OW transition cannot definitely be converted into a primary productivity increase. It represents however an increase in biomass which differentiates the waters in the northeast from the oligotrophic waters of the South Pacific central gyre. Southwest of the observed SSCC increase, the possibility that surface waters with a low chlorophyll content cap an active chlorophyll maximum cannot be excluded. The chlorophyll maximum at or near the surface in divergent zones is expected to sink and progressively weaken at convergences (Vinogradov et al. 1970); our UW-OW transition detected at the sea surface might then underestimate rather than overestimate the width of the enriched zone.

\section{CONCLUSION}

A large fraction of the organic matter synthesized in the Southeastern Pacific upwellings is exported through the zone studied in the present work. Few oceanographic cruises including biological observations have been organized between the Tuamotu islands and the Galapagos islands, so that this region is only known through a few sets of data covering short periods. Our data, which cover the period from December 1979 to September 1985 at a mean rate of one transect every $13 \mathrm{~d}$, show that mesoscale variability is important. The UW-OW transition moves rapidly on time scales of about 1 mo or less. Seasonal variations may be important for the absolute chlorophyll concentrations on the northern side of the transition, but they do not seem to influence the position of the transition. On the track between Tahiti and Panama, 95\% of the transitions are found betwen 5 and $17^{\circ} \mathrm{S}$; the area between these extremes is characterized by alternation of the upwelling and oligotrophic ecosystems. Pelagic communities which accompany the water masses are probably not affected by these oscillations. However, benthic communities on the archipelagos of this region alternately live in oligotrophic and upwelled waters. The 2 regimes should be considered when the ecology of these communities is studied.
The South Equatorial Current waters are enriched by the upwelling off South America and the equatorial upwelling. High SSCC in these waters is then generally the rule. On the other hand, eastward flows transport oligotrophic water with low SSCC. Convergences between these 2 flows are then likely to produce frontal zones for which the UW-OW transitions discussed here are a coarse representation, due to sampling 75 to $110 \mathrm{~km}$ apart for both SSCC and XBTs. Temperature contrasts in this region are often weak, and the relationship shown here between the UW-OW transition and eastward-westward flow convergences suggests that the sea color measured by satellites would perhaps be a better indicator of these flows. Very incomplete knowledge of the eastward flows in the South Tropical Pacific Ocean makes it an interesting proposition to analyse sea color satellite data in this region.

Acknowledgements. We are grateful to the captains and crews of M.S. Cezanne, Gauguin, Rodin, Rostand, Rousseau, and Utrillo of the Compagnie Générale Maritime for kind and careful sampling at sea. We also thank Henri Walico for his help in chlorophyll measurements, and Maryse Sicard and Marie-José Langlade for attending to the XBT data bank. XBT probes were provided by the US-NOAA under an agreement between ORSTOM and the Scripps Institution of Oceanography

\section{LITERATURE CITED}

Bacastow, R. B., Adams, J. A., Keeling, C. D., Moss, D. J., Worf, T P., and Wong, C. S. (1980). Atmospheric carbon dioxide, the Southern Oscillation, and the weak $1975 \mathrm{El}$ Niño. Science 210: 66-68

Barber, R. T., Chavez, F. P. (1983). Biological consequences of El Niño. Science 222: 1203-1210

Dandonneau, Y. (1982). A method for the rapid determination of chlorophyll plus phaeopigments in samples collected by merchant ships. Deep Sea Res. 29: 647-654

Dandonneau, $Y$ (1986). Monitoring the sea surface chlorophyll concentration in the Tropical Pacific: consequences of the 1982-1983 El Niño. Fish. Bull. U.S. 84: $687-695$

Dandonneau, Y., Charpy, L. (1985). An empirical approach to the island mass effect in the South Tropical Pacific based on sea surface chlorophyll concentrations. Deep Sea Res. 32: $707-721$

Dandonneau, Y., Gohin, F. (1984). Meridional and seasonal variations of the sea surface chlorophyll concentration in the southwestern tropical Pacific $\left(14\right.$ to $32^{\circ} \mathrm{S}, 160$ to $175^{\circ}$ E). Deep Sea Res. 31: 1377-1393

Desrosieres, R., Wauthy, B. (1972). Distribution du phytoplancton et structure hydrologique dans la région des Tuamotu (Océan Pacifique Central). Cah. O.R.S.T.O.M. (sér. océanogr.) 10: 275-287

Dessier, A. (1983). Variabilité spatiale et saisonnière des peuplements épiplanctoniques des copépodes du Pacifique tropical sud et equatorial (Est Pacifique). Oceanologica Acta 6: 89-103

Dessier, A., Donguy, J. R. (1985). Planktonic copepods and environmental properties of the eastern equatorial Pacific: 
seasonal and spatial variations. Deep Sea Res. 32 $1117-1133$

Eldin, G. (1983). Eastward flows of the South Equatorial Central Pacific. J. Phys. Oceanogr. 13: 1461-1467

Feldman, G. C. (1986). Patterns of phytoplankton production around the Galapagos islands. In: Bowman, J., Yentsch, M., Peterson, W T (ed.), Tidal mixing and plankton dynamics. Springer-Verlag, Heidelberg, p. 77-106

Hayward, T. L., Venrick, E. L. (1982). Relation between surface chlorophyll, integrated chlorophyll, and integrated primary production. Mar. Biol. 69: 247-252

Iverson, R. L. (1977). Mesoscale oceanic phytoplankton patchiness caused by hurricane effects on nutrient distribution in the Gulf of Mexico. In: Andersen, N. R., Zahuranec, B. J. (ed.) Oceanic sound scattering prediction. Plenum Press, New York, p. 767-778

Koblentz-Mishke, O. J., Volkovinsky, V V., Kabanova, J. G. (1970). Plankton primary production of the world ocean. In: Wooster, W. S. (ed.) Scientific exploration of the southern Pacific. National Academy of Sciences, Washington, D. C., p. $183-193$

Lorenzen, C. J. (1970). Surface chlorophyll as an index of the depth, chlorophyll content, and primary productivity of the euphotic layer. Limnol. Oceanogr. 7: 479-480

McGowan, J. A. (1974). The nature of oceanic ecosystems. In Miller, C. B. (ed.) The biology of the Pacific Ocean. Oregon State University Press, Corwallis, p. 9-28

Owen, R. W., Zeitzschel B. (1970). Phytoplankton production: seasonal change in the oceanic eastern tropical Pacific. Mar. Biol. 7: 32-36

Platt, T., Hermann, A. (1983). Remote sensing of phytoplankton in the sea: surface-layer chlorophyll as an estimate of water-column chlorophyll and primary production. Int. J. Remote Sens. 4: 343-351

Robinson, M. K. (1976). Atlas of North Pacific Ocean monthly mean temperatures and mean salinities of the surface layer Ref. Publ. 2, 173 fig. Naval Oceanogr. Office, Washington, D. C.

Rougerie, F., Wauthy, B. (1986). Le concept d' endo-upwelling dans le fonctionnement des atolls-oasis. Oceanol. Acta 9: $133-148$

Showers, W. J. (1982). Isotropic trends in calcareous plankton across the equatorial Padific high productivity zone. Ph. D. dissertation, University of Hawaii, Honolulu

Thomas, W. H. (1972). Nutrient inversions in the southeastern tropical Pacific Ocean. Fish. Bull. U.S. 70: 929-932

Thomas, W H. (1979). Anomalous nutrient-chlorophyll interrelationships in the eastern tropical Pacific Ocean. J. mar. Res. 37: 327-335

Tsuchiya, M. (1974). Variations of the surface geostrophic flow in the eastem intertropical Pacific Ocean. Fish. Bull. U.S. 72: 1075-1086

Vinogradov, M. E., Gitelzon, I. I., Sorokin, Y L. (1970). The vertical structure of a pelagic community in the tropical ocean. Mar. Biol. 6: 187-194

Walsh, J. J. (1976). Herbivory as a factor in patterns of nutrient utilization in the sea. Limnol. Oceanogr. 21: 1-13

Walsh, J. J. (1981). A carbon budget for overfishing in Peru. Nature, Lond. 290: 300-304

Wyrtki, K. (1981). An estimate of equatorial upwelling in the Pacific. J. Phys. Oceanogr. 11: 1205-1214

Wyrtki, K. Eldin, G. (1982). Equatorial upwelling events in the Central Pacific. J. Phys. Oceanogr. 12: 984-988 